\title{
SECOND EYE CATARACT SURGERY: PERCEPTIONS OF A POPULATION ASSISTED AT A UNIVERSITY HOSPITAL
}

\author{
Amaryllis Avakian, Edmea Rita Temporini, and Newton Kara-José
}

\begin{abstract}
Avakian A, Temporini ER, Kara-José N. Second eye cataract surgery: Perceptions of a population assisted at a university hospital. Clinics. 2005;60(5):401-6.
\end{abstract}

OBJECTIVE: To identify daily life difficulties perceived by patients suffering from senile cataract before and after second eye cataract surgery.

METHODS: Longitudinal prospective study with 84 patients consecutively seen within the framework of the Cataract Project, with visual acuity equal to or higher than 20/30 in the pseudophakic eye, and equal to or lower than 20/40 with the best possible optical correction in the cataractous eye. A questionnaire was applied during an interview.

RESULTS: Before surgery, 60.7\% complained about visual impairment (moderate or marked); after surgery, $92.8 \%$ had no difficulty. Routine activities, mobility, and leisure activities were significantly altered after surgery $(P=.001)$.

CONCLUSION: According to the patients' perceptions, there was a significant reduction in visual difficulties after second eye cataract surgery.

KEYWORDS: Senile cataract. Second eye cataract surgery. Patients' perceptions. Routine activities. Ophthalmology in Public Healthcare.

Cataract is considered the major cause of blindness ${ }^{1}$ and visual impairment in adults above 60 years of age. ${ }^{2}$ As life expectacy rises in developing countries, the number of individuals legally blind from cataract is expected to increase, and critical levels are foreseen for the future. ${ }^{3,4}$ Although worldwide, this is the most frequently performed surgical procedure in elderly people, the number of surgeries is still insufficient, if we consider the estimated incidence of cataract. ${ }^{5}$ With the objective of reducing the rates of visual loss, large-scale cataract surgery programs have been encouraged worldwide. Since 1987, a program has been developed in the State of São Paulo for the prevention of cataract-related visual loss, consisting of several projects entitled the Cataract Project. The Cataract Project seeks to eliminate

Discipline of Ophthalmology, Hospital das Clínicas, Faculty of Medicine, University of São Paulo - São Paulo/SP, Brazil.

Email: aavakian@uol.com.br

Received for publication on June 10, 2005.

Accepted for publication on July 28, 2005. logistical barriers that prevent the patient with cataract-related visual impairment from receiving the necessary treatment, facilitate the access to ophthalmologic examination and surgery, and provide education to the public. ${ }^{6}$

In Brazil, there is an estimated need for 500,000 cataract surgeries per year to meet the national demand and eradicate cataract-related visual loss ${ }^{4}$; however, until 1998, only 100,000 surgical procedures were performed each year. ${ }^{7}$ Since 1999, through the joint efforts of the Health Ministry and the Brazilian College of Ophthalmology, the number of surgical interventions performed in the public healthcare system units has been increasing, having reached 153,000 procedures in $1999,228,200$ procedures in 2000 , 267,000 procedures in 2001 , and 320,000 procedures in $2002 .^{8}$ However, in spite these initiatives, the cumulative number of non-operated cases of cataract is increasing, and the disease continues to be an important issue for the Public Healthcare System in Brazil, especially in remote, difficult-access regions. 
Second eye surgery represents a substantial part of the total number of cataract surgeries. ${ }^{9}$ In the United States, United Kingdom, and Sweden, it is estimated that approximately one third of the patients who undergo cataract surgery have the second eye surgery done within 12 months of the first procedure, and this proportion has tended to grow. ${ }^{10,11}$ On a worldwide basis, significant rates of legal blindness are confirmed: 1,000,000 cataract surgical procedures are still performed in bilaterally blind people. ${ }^{12}$

Considering cataract surgery, most analyses focus on the changes that take place after the first eye surgery, ${ }^{13}$ showing an improvement in objective visual acuity, subjective visual function, and quality of life. ${ }^{14,15,16}$ In Brazil, no studies have been reported concerning the cost-benefit analysis of the second eye surgery or the benefits for the population. There are few studies on the perceptions of subjects undergoing second eye cataract surgery in relation to the beneficial effects on open eye binocular vision and the performance of daily activities.

This study aimed at identifying the daily life difficulties perceived by patients suffering from senile cataract, before and after undergoing second eye cataract surgery, at the outpatient surgical facilities of a university hospital.

\section{METHODS}

A longitudinal prospective study was carried out among the population of patients suffering from unilateral senile cataract, assisted by the Cataract Project at the University of São Paulo Medical School General Hospital (HCFMUSP) or registered at the Ophthalmology Outpatient Unit of the HC-FMUSP, during the period from January to June 2002. These subjects had already undergone unilateral cataract surgery with intraocular lens implant; they were informed about the study objectives, asked for consent to participate, and assured of confidentiality and anonymity with respect to their personal information. They were included after giving their written and signed informed consent.

The following were the inclusion criteria: age equal to or above 45 years; pseudophakia for at least 4 months; visual acuity (VA) equal to or above 20/30 in the pseudophakic eye, equal to or below 20/40 in the cataractous eye with the best possible optical correction; capacity to understand and answer the planned questionnaire. Patients with ocular changes other than cataract were excluded.

The following parameters were analyzed: perception of visual impairment in relation to daily life activities (reading, working, leisure, domestic chores, mobility, or driving) before and after surgery, age, and performance of occupational tasks.
The data were obtained by interviewing the patients and applying the questionnaire, which was elaborated based on a preliminary study that allowed the construction of structured questions. The questionnaire was previously tested by application on 23 patients with similar characteristics to those of the study sample.

For the statistical analysis, the chi-square test was used to compare proportions, using a significance level of $1 \%$.

\section{RESULTS}

The sample consisted of 84 subjects, aged between 45 and 83 years, with an average age of $66.0 \pm 9.3$ years. Among those who had discontinued their professional activities $(58.3 \%), 65.3 \%$ confirmed that this was due to the ocular disorder.

Concerning the degree of perceived visual impairment, $60.7 \%$ reported medium or marked impairment before surgery. This degree of impairment was reported by only $1.2 \%$ of the subjects after the second eye surgery. On the other hand, $92.8 \%$ of the subjects reported no visual impairment after the second eye surgery (Table 1 ).

Table 1 - Perception of patients about their own visual impairment before and after second eye surgery (University of São Paulo Medical School General Hospital, 2002)

\begin{tabular}{lcccc}
\hline & \multicolumn{2}{c}{ Total $\mathrm{n}=84$} \\
\hline Difficulty & \multicolumn{2}{c}{ Before surgery } & \multicolumn{2}{c}{ After surgery } \\
& $\mathrm{n}$ & $\%$ & $\mathrm{n}$ & $\%$ \\
\hline None & 18 & 21.4 & 78 & 92.8 \\
Little & 15 & 17.9 & 5 & 6.0 \\
Medium & 29 & 34.5 & 1 & 1.2 \\
High & 22 & 26.2 & - & - \\
\hline
\end{tabular}

$X^{2}=90.63 P=.0001$

The activities involving mobility (taking a bus, climbing up or down stairs and watching out for the sidewalk curb, walking without bumping) were mentioned as difficult by $59.5 \%, 64.3 \%$, and $42.9 \%$ of the subjects, respectively. These percentages significantly changed after surgery $(P=.0001)$ (Table 2$)$.

Concerning leisure activities, watching TV was difficult for $48.8 \%$, crocheting or knitting for $17.8 \%$, and visiting friends for $38.1 \%$. After surgery, it was observed that these results tended towards $0 \%(P=.0001, P=.0006$, and $P=.0001$, respectively) (Table 3 ). Differences in routine activities observed before and after cataract surgery were highly significant. For example, for threading a needle, $67.9 \%$ reported difficulties before surgery, while only $3.6 \%$ still had difficulty after surgery $(P=.0001)$. For picking rice, beans, and washing vegetables, from the $46.4 \%$ who 
reported difficulties before surgery, only $1.2 \%$ still had difficulties after surgery $(P=.0001)$. For activities such as nailing, screwing, fixing things, or shopping and reading price tags, referred to as difficult before surgery by $54.8 \%$ and $54.7 \%$, respectively, only $1.2 \%$ of the patients still had difficulties after the cataract surgery $(P=.0001)$ (Table 4).

Table 2 - Difficulties in patient mobility before and after second eye surgery (University Of São Paulo Medical School General Hospital, 2002)

\begin{tabular}{|c|c|c|c|c|}
\hline \multirow{3}{*}{ Activity/difficulty } & \multicolumn{4}{|c|}{ Total $n=84$} \\
\hline & \multicolumn{2}{|c|}{ Before surgery } & \multicolumn{2}{|c|}{ After surgery } \\
\hline & $\mathrm{n}$ & $\%$ & $\mathrm{n}$ & $\%$ \\
\hline \multicolumn{5}{|c|}{ TAKING THE BUS } \\
\hline It is difficult & 50 & 59.5 & 1 & 1.2 \\
\hline It is not difficult & 26 & 31.0 & 75 & 89.3 \\
\hline Does not do it & 8 & 9.5 & 8 & 9.5 \\
\hline \multicolumn{5}{|c|}{$\mathrm{X}^{2}=70.85 \mathrm{P}=.0001$} \\
\hline \multicolumn{5}{|c|}{$\begin{array}{l}\text { CLIMBING STAIRS, } \\
\text { WATCHING THE } \\
\text { SIDEWALK }\end{array}$} \\
\hline It is difficult & 54 & 64.3 & - & - \\
\hline It is not difficult & 30 & 35.7 & 84 & 100.0 \\
\hline Does not do it & - & - & - & - \\
\hline \multicolumn{5}{|c|}{$\mathrm{X}^{2}=76.88 \mathrm{P}=.0001$} \\
\hline \multicolumn{5}{|l|}{$\begin{array}{l}\text { WALK WITHOUT } \\
\text { BUMPING }\end{array}$} \\
\hline & 36 & & 1 & 1.2 \\
\hline It is not difficult & 48 & 57.1 & 83 & 98.8 \\
\hline Does not do it & - & - & - & - \\
\hline
\end{tabular}

Table 3 - Difficulties in performing leisure activities before and after contralateral eye surgery (University Of São Paulo Medical School General Hospital, 2002)

\begin{tabular}{|c|c|c|c|c|}
\hline & & & & tal $n=84$ \\
\hline \multirow[t]{2}{*}{ Activity/difficulty } & \multicolumn{2}{|c|}{ Before surgery } & \multicolumn{2}{|c|}{ After surgery } \\
\hline & $\mathrm{n}$ & $\%$ & $\mathrm{n}$ & $\%$ \\
\hline \multicolumn{5}{|l|}{ WATCH TV } \\
\hline It is difficult & 41 & 48.8 & 1 & 1.2 \\
\hline It is not difficult & 42 & 50.0 & 82 & 97,6 \\
\hline Does not do it & 1 & 1.2 & 1 & 1.2 \\
\hline \multicolumn{5}{|c|}{$X^{2}=51.00 P=.0001$} \\
\hline \multicolumn{5}{|l|}{$\begin{array}{l}\text { CROCHETING, } \\
\text { KNITTING }\end{array}$} \\
\hline It is difficult & 15 & 17.8 & - & - \\
\hline It is not difficult & 5 & 6.0 & 20 & 23.8 \\
\hline Does not do it & 64 & 76.2 & 64 & 76.2 \\
\hline \multicolumn{5}{|c|}{$X^{2}=24.00 P=.0006$} \\
\hline \multicolumn{5}{|c|}{ VISITING FRIENDS } \\
\hline It is difficult & 32 & 38.1 & - & - \\
\hline It is not difficult & 51 & 60.7 & 83 & 98.8 \\
\hline Does not do it & 1 & 1.2 & 1 & 1.2 \\
\hline
\end{tabular}

Table 4 - Difficulties in performing routine activities before and after contralateral eye surgery (University Of São Paulo Medical School General Hospital, 2002)

Total $\mathrm{n}=84$

\begin{tabular}{|c|c|c|c|c|}
\hline Activity/difficulty & & gery & & \\
\hline & $\mathrm{n}$ & $\%$ & $\mathrm{n}$ & $\%$ \\
\hline SHAVING & & & & \\
\hline It is difficult & 18 & 21.4 & - & - \\
\hline It is not difficult & 23 & 27.4 & 41 & 48.8 \\
\hline Does not do it & 43 & 51,2 & 43 & 51.2 \\
\hline$X^{2}=23.06 P=.00$ & & & & \\
\hline THREAD A NEED & & & & \\
\hline It is difficult & 57 & 67.9 & 3 & 3.6 \\
\hline It is not difficult & 11 & 13.1 & 65 & 77.4 \\
\hline Does not do it & 16 & 19.0 & 16 & 19.0 \\
\hline$X^{2}=86.97 P=.00$ & & & & \\
\hline $\begin{array}{l}\text { PICK RICE, BEAI } \\
\text { WASH VEGETAB }\end{array}$ & & & & \\
\hline It is difficult & 39 & 46.4 & 1 & 1.2 \\
\hline It is not difficult & 24 & 28.6 & 62 & 73.8 \\
\hline Does not do it & 21 & 25.0 & 21 & 25.0 \\
\hline
\end{tabular}

NAIL, SCREW,

FIX THINGS

\begin{tabular}{lllcc}
\hline It is difficult & 46 & 54.8 & 1 & 1.2 \\
It is not difficult & 21 & 25.0 & 66 & 78.6 \\
Does not do it & 17 & 20.2 & 17 & 20.2 \\
\hline$X^{2}=66.36 P=0.0001$ & & &
\end{tabular}

DISHWASHING,

WASHING AND

IRONING CLOTHES

\begin{tabular}{llccc}
\hline It is difficult & 29 & 34.5 & 1 & 1.2 \\
It is not difficult & 40 & 47.6 & 68 & 80.9 \\
Does not do it & 15 & 17.9 & 15 & 17.9 \\
\hline
\end{tabular}

$X^{2}=33.39 P=.0006$

PUT THINGS IN

ORDER AT HOME

\begin{tabular}{lcccc}
\hline It is difficult & 35 & 41.6 & - & - \\
It is not difficult & 46 & 54.8 & 81 & 96.4 \\
Does not do it & 3 & 3.6 & 3 & 3.6 \\
\hline$X^{2}=44.65 P=0.0001$ & & & & \\
\hline SERVE WATER, P & & & & \\
OUR COFFEE IN CUP & & & & \\
\hline It is difficult & 41 & 48.8 & 1 & 1.2 \\
It is not difficult & 43 & 51.2 & 83 & 98.8 \\
Does not do it & - & - & - & - \\
\hline$X^{2}=48.29 P=.0001$ & & & & \\
\hline GO SHOPPING, & & & & \\
READ PRICE TAGS & & & & \\
\hline It is difficult & 46 & 54.7 & 1 & 1.2 \\
It is not difficult & 33 & 39.3 & 78 & 92.8 \\
Does not do it & 5 & 6.0 & 5 & 6.0 \\
\hline$X^{2}=61.33 P=.0001$ & & & & \\
\hline
\end{tabular}

PUT THINGS ON

TABLE, SHELF

\begin{tabular}{lcccc}
\hline It is difficult & 27 & 32.1 & 1 & 1.2 \\
It is not difficult & 56 & 66.7 & 82 & 97,6 \\
Does not do it & 1 & 1.2 & 1 & 1.0 \\
\hline$X^{2}=29.04 P=.0005$ & & & &
\end{tabular}




\section{DISCUSSION}

Considering the available healthcare resources and their optimization, there is controversy concerning bilateral cataract surgery..$^{10}$ In Brazil, as in many other countries, there has been an increase in the number of cataract surgeries performed, with better visual outcomes and patient satisfaction. Consequently, there is a natural tendency for $30 \%$ to $40 \%$ of the subjects suffering from bilateral cataract to seek surgical care for both eyes. Considering bilateral blindness rates, as well as resource availability, the decision to perform second eye surgery represents an incremental cost of $40 \%$ that must be covered by a scarcely sufficient healthcare budget. ${ }^{7}$ That makes it essential to obtain information on the perceived visual impairment in subjects having already undergone cataract surgery in one eye, in order to define guidelines for tertiary care, which is the ultimate objective of this study. All the evidence indicates that incremental gains in visual function and quality of life may be obtained after the contralateral eye surgery, suggesting that the importance of such procedure should not be neglected.

In this study, the average age was $66.0 \pm 9.3$ years (ranging from 45 to 83 years), similar to that reported by KaraJosé Jr et $\mathrm{al}^{17}$ and Temporini et $\mathrm{al}^{18}$ for the Cataract Project, which were respectively 70 years and 71.6 years, on average. These data are consistent with the nature of the procedure being studied, i.e., second eye cataract surgery.

If we consider the age average (66.0 years) and the fact that most subjects interviewed were no longer engaged in professional activities $(58.3 \%)$, we can estimate the economic burden represented by loss of visual acuity in this age group, where people could still be performing productive activities.

Studies conducted in Brazil with patients assisted by the Cataract Project, ${ }^{17,19}$ have indicated that $70 \%$ to $80 \%$ of the patients had stopped performing professional activities, which is higher than the rate found in this study (58.3\%), despite the fact that both populations had similar age ranges. The difference may be related to the analysis of different samples and visual conditions, with cataract-blind subjects in the above mentioned studies while this study's sample consisted of patients with visual impairment due to unilateral cataract.

The patients analyzed in this study had undergone first eye surgery at least 4 months before the start of the study. Nevertheless, during the pre-operative visit, the majority $(65.3 \%)$ reported discontinuation of their professional activities due to the visual problems. The fact that the study population that was evaluated has not resumed professional activities after the first eye surgery may indicate, among other things, an unwanted delay in the performance of the surgical procedure.

Concerning perception of visual impairment, most subjects, despite VA equal to or above 20/30 in the pseudophakic eye, reported moderate or marked visual impairment (Table 1), a finding also observed in the study from Talbot and Perkins. ${ }^{20}$ After the surgical intervention, there was a decrease in the reported symptoms of visual impairment, possibly related to the binocular inhibition phenomenon, which has been described in patients with unilateral cataract. ${ }^{21}$

The subjects reported difficulties in mobility and performing routine or leisure activities (Tables 2, 3, and 4). Lundström et $\mathrm{al}^{22}$ have also surveyed the difficulties perceived by elderly patients with senile cataract and found similar problems concerning mobility, social life, reading, domestic chores, leisure activities, watching TV, and traveling.

In relation to mobility, affecting such tasks as taking the bus, climbing up and down stairs watching the sidewalk curb, and walking without bumping, there was evident improvement after intervention (Table 2). The improved mobility is possibly related to the improvement in VA, as well as in peripheral vision and/ or stereopsis, resulting from surgery. Coday et $\mathrm{al}^{23}$ also found changes in mobility in patients with monocular vision, but this was observed in $39 \%$ of the patients, a lower rate than in the present study. In relation to the frequency of bumping into people and objects, they noted a worsening of the problem in subjects with low monocular VA that was due to changes in the peripheral visual field.

Concerning difficulties in performing daily life and leisure activities, such as watching TV, visiting friends, shaving, sewing, and domestic chores, a significant benefit was observed after surgery in the contralateral eye (Tables 3 and 4), suggesting an improvement in these patients' quality of life. Other studies have reported on the activities discontinued by people with cataract as a result of visual impairment, such as regularly watching TV (22.6\%) and handcraft (19.4\%). ${ }^{17}$

For those tasks directly related to binocular vision (pouring liquids into receptacles and placing objects on tables and shelves), the improvement after surgical intervention was equally evident (Table 4). Other studies had already shown the difficulties of pouring liquids into small containers and of reaching for objects for subjects with monocular vision. ${ }^{23}$ In these patients, even those activities apparently unrelated to binocular vision, such as watching television, may also be affected, due to the phenomenon of binocular suppression or rivalry that could make the open eye binocular vision worse than monocular vision in the best eye alone..$^{21,23}$ 
Since subjects who underwent successful first eye cataract surgery still perceived visual limitations, the second eye intervention was considered beneficial. According to these patients' perceptions, there was a significant decrease in the reported difficulties after second eye cataract surgery, showing that this procedure contributed significantly to improving the performance of daily activities in this group of people.

\section{RESUMO}

Avakian A, Temporini ER, Kara-José N. Cirurgia de catarata no Segundo olho: Percepção de população atendida em Hospital Universitário. Clinics. 2005;60(5):401-6.

OBJETIVO: Identificar dificuldades na vida diária percebidas por pacientes com catarata senil, antes e após a cirurgia de catarata no segundo olho.

MÉTODOS: Estudo longitudinal prospectivo de 84 pacientes consecutivos atendidos por "Projeto Catarata", com acuidade visual maior ou igual a 20/30 no olho pseudofácico e menor ou igual a 20/40 with the best possible optical correction no olho com catarata. Aplicou-se ques- tionário por entrevista.

RESULTADOS: Antes da cirurgia 60,7\% declararam dificuldade visual (média ou muita); após, 92,8\% nenhuma dificuldade. Atividades rotineiras, de mobilidade e lazer alteraram-se significativamente após a cirurgia $(\mathrm{p}=0,001)$. CONCLUSÃO: Na percepção dos pacientes, após a cirurgia de catarata do segundo olho houve redução importante das dificuldades visuais.

UNITERMOS: Catarata senil. Cirurgia de catarata no segundo olho. Percepção de pacientes. Atividades cotidianas. Oftalmologia em Saúde Pública.

\section{REFERENCES}

1. de Senne FMB, Cardillo JA, Rocha EM, Kara-José N. Long-term visual outcomes in the cataract-free zone project in Brazil. Acta Ophthalmol Scand. 2002;80(3):262-6.

2. Carvalho KM, Monteiro GBM, Isaac CR, Shiroma LO, Amaral MS Causes of low vision and use of optical aids in the elderly. Rev Hosp Clin Fac Med S Paulo. 2004;59:157-60.

3. Limburg H, Kumar R. Follow-up study of blindness attributed to cataract in Karnataka State, India. Ophthalmic Epidemiol. 1998;5(4):211-23.

4. Kara-José Jr N, Arieta CEL. Catarata Senil. In: Kara-José N, Almeida GV. Senilidade Ocular. São Paulo, Roca, 2001. p. 99.

5. Frick KD, Foster A. The magnitude and cost of global blindness: an increasing problem that can be alleviated. Am J Ophthalmol. 2003;135(4):471-6

6. Kara-José N, Temporini ER. Cirurgia de catarata o porquê dos excluídos. Rev Panam Salud Publica. 1999;6(4):242-8.

7. Kara-José N, Delgado AMN, Arieta CEL. Catarata. In: Rodrigues MLV Oftalmologia Clínica. Rio de Janeiro, Cultura Médica, 1992. p. 288.
8. Relatório do Conselho Brasileiro de Oftalmologia: Campanha Nacional de Cirurgias de Catarata. www.cbo.com.br/cbo/campanhas_sociais.htm

9. DesaiI P, Reidy A, Minassian DC. Profile of patients presenting for cataract surgery in the UK: national data collection. Br J Ophthalmol. 1999;83(8):893-6

10. Claridge KG, Francis PJ, Bates AK. Should second eye cataract surgery be rationed? Eye. 1995;9(Pt.6 Suppl):47-9.

11. Castells X, Alonso J, Ribó C, Nara D, Teixido A, Castilla M. Factors associated with second eye cataract surgery. Br J Ophthalmol. 2000;84(1):9-12.

12. Foster A. Cataract- A global perspective: output, outcome and outlay. Eye. 1999;13(Pt 3b):449-53.

13. Javitt JC, Steinberg EP, Sharkey P, Schein OD, Tielsch JM, Diener M et al. Cataract surgery in one eye or both. A billion dollar per year issue. Ophthalmology. 1995;102(11):1583-93.

14. Bernth-Petersen P. Outcome of cataract surgery I: A prospective, observational study. Acta Ophthalmol. 1982;60(2):235-42. 
15. Applegate WB, Miller ST, Elam JT, Freeman JM, Wood TO, Gettlefinger TC. Impact of cataract surgery with lens implantation on vision and physical function in elderly patients. JAMA. 1987;257(8):1064-6.

16. Legro MW. Quality of life and cataracts: A review of patient-centered studies of cataract surgery outcomes. Ophthalmic Surg. 1991;22(8):43143.

17. Kara-José Jr N, Schellini SA, Silva MRBM, Bruni LF, Almeida AGC. Projeto Catarata- Qual a sua importância para a comunidade? Arq Bras Oftalmol. 1996;59(5):490-96.

18. Temporini ER, Kara-José Jr N, Kara-José N, Holzchuh N. Popular beliefs regarding the treatment of senile cataract: Concepções populares do tratamento da catarata senil. Rev Saúde Pública. 2002;36(3):343-9.

19. Temporini ER, Kara-José N, Kara-José Jr N. Catarata senil: características e percepções de pacientes atendidos em projeto comunitário de reabilitação visual. Arq Bras Oftalmol. 1997;60(1):7983.
20. Talbot EM, Perkins A. The benefit of second eye cataract surgery. Eye. 1998;12(Pt 6):983-9.

21. Laidlaw DA, Harrad RA, Hopper CD, Whitaker A, Donovan JL, Brookes ST et al. Randomised trial of effectiveness of second eye cataract surgery. Lancet. 1998;352(9132):925-9.

22. Lundstrom M, Fregell G, Sjoblom A. Vision related daily life problems in patients waiting for a cataract extraction. Br J Ophtalmol. 1994;78(8):608-11

23. Coday MP, Warner MA, Jahrling KV, Rubin PA. Acquired monocular vision: functional consequences from the patient's perspective. Ophthal Plast Reconstr Surg. 2002;18(1):56-63. 